\title{
Comparative Analysis of Compliance between Rivaroxaban with Heparin and Warfarin in the Management of Deep Vein Thrombosis at Tertiary Care Hospital, Larkana
}

Muhammad Aslam Abbasi ${ }^{1}$, Muhammad Ali Ghoto ${ }^{2}$, Mudassar lqbal Arain ${ }^{2, *}$, Abdullah Dayo ${ }^{1}$, Sajid Ali

Mojai ${ }^{3}$, Rabia Parveen ${ }^{2}$, Ramesha Anwar ${ }^{2}$

${ }^{1}$ Department of Pharmaceutics, Faculty of Pharmacy, University of Sindh, Jamshoro Pakistan.

${ }^{2}$ Department of Pharmacy Practice, Faculty of Pharmacy, University of Sindh, Jamshoro Pakistan.

${ }^{3}$ Department of Pharmacy, Shah Abdul Latif University, Khairpur, Pakistan.

\begin{tabular}{l} 
Authors' Contributions \\
1 Data Collection \& Processing. \\
2,3 Conception \& Study design. \\
4 Critical Review. \\
5 Drafting of Manuscript. \\
6 Data Analysis. \\
7 Drafting of Manuscript. \\
\hline Acknowledgement \\
\hline Article info. \\
Received: September 28, 2020 \\
Accepted: December 18, 2020 \\
\hline Funding Source: Nil \\
Conflict of Interest: Nil \\
\hline Cite this article: Abbasi M A, Ghoto M A, \\
Arain M I, Dayo A, Mojai S A, Parveen R, \\
Anwar R. Comparative Analysis of Compliance \\
between Rivaroxaban with Heparin and \\
Warfarin in the Management of Deep Vein \\
Thrombosis at Tertiary Care Hospital, Larkana. \\
RADS J Pharm Pharm Sci. 2020; 8(3):141- \\
146.
\end{tabular}

*Address of Correspondence Author: mudassar.arain@usindh.edu.pk

\begin{abstract}
A B S T R A C T
Objective: The objective behind this study is to evaluate the compliance and noncompliance, between standard therapy with latest oral anticoagulants (NOACs) with each other so as a head-to-head comparison will ever be available.
\end{abstract}

Methodology: A descriptive observational study was conducted at SMBBMUH Larkana.The questionnaire (specially designed) was filled up to monitor the non-compliances associated with drugs used for the management of Deep Vein Thrombosis (DVT).The study was conducted on the 100 patients who were reported with DVT at tertiary care hospital SMBBMUH Larkana. A series of questions were asked from reported patients regarding symptoms and side effects. Finally the results were analyzed by using descriptive statistics.

Results: Results show that out of 100 patients, male patients (79\%) observed more than female (21\%) and mostly patients perform indoor jobs (39\%). Prevalence of DVT is high about $53 \%$ patients were suffering from DVT during 03 months. It was found that mostly patient non compliance observed with Warfarin $(n=26)$ as compare to heparin $(n=19)$ and Rivaroxaban $(n=07)$.

Conclusion: The study concluded that the more compliance achieved with Rivaroxaban as compared to warfarin and heparin. Mostly noncompliant factors are cost; prolong therapy, adverse drug reaction were common factors of non compliance in DVT patients.

Keywords: Deep vein thrombosis, Heparin, Pulmonary embolism, Coagulation.

\section{INTRODUCTION}

With the improvement of new generation oral anticoagulants like factor $\mathrm{Xa}$ inhibitors gives us new available choice. This study will also help us in determining the best alternatives in DVT with, Cost, Side effects, Drug-drug Interactions (DDI), Drug food Interactions (DFI), chances of major bleeding, Coagulation monitoring [1].DVT is a frequent complication which can affect both genders i.e. male 
and female.Although incidence with male is relatively higher [2]. It not only affects surgical patients but also acutely ill hospitalized patients. It may also affect persons who remain static for a longer period or having long flights [3]. For many years, Heparins and Warfarin have been used as first line therapy in Venous Thromboembolism (VTE).

The Thrombosis can be defined as "process in which the blood cells clumps together to form aggregates inside the blood vessels and causes resistance in flow of blood inside the circulatory system is called as thrombosis". Thrombosis occurs when the walls of blood vessels damaged.The body utilizes platelets and fibrin so they stick together to form aggregates to stop the blood loss. If the thrombosis occurs in the vein then it is called as Venous Thrombosis. Venous thrombosis may cause the blockage of vein. If the thrombosis occurs in the artery, than it is called as Arterial Thrombosis $[4,5]$.The arterial thrombosis is just mild or moderate rarely it becomes sever.Whereas the venous thrombosis may influence the blood supply results damage of tissue which is supplied by that artery. When the blood clot which dislodged from other site in the circulatory system obstructsthe blood vessels is called as Thromboembolism. When blood clot obstructs blood vessels in lungs called as Pulmonary Embolism. If blood clot obstruct blood vessels in brain than it is called as Stroke. It may also obstruct the blood vessels in gastro intestinal tract, kidney or legs. The drugs such as warfarin, heparins are prescribed to cure the Thrombosis $[6,7]$.

Deep Vein Thrombosis occurs when the thrombus formation occurs in one or more than one veins which are much more away in the body or in a deep vein in the body most commonly in legs. It can also occur if a person cannot move for a longer period of time due to any reason.Deep Vein Thrombosis can be travel through your circulation system and enter in the lungs, blocking blood stream (Pulmonary Embolism)[8].

There are two fundamental classes of DVT, and they depend on how long the blood coagulation is available. Acute DVT can be defined as"When a blood clot develops and has been around for 14 days or less, at that point it is called acute DVT". Chronic DVT can be defined as "When the blood clot continues for 28 days or more, than it is called chronic DVT" $[9,11]$.
The main causes of a blood clot in a deep vein thrombosis (DVT) are, slowed blood stream, abnormal coagulating issues, medical procedure or a physical issue to the veins, malignancy can likewise cause DVT [13]. DVT ordinarily frames in a single leg or one arm. Not every person with a DVT will have indications, yet side effects can include; Swelling of the leg or arm, Pain or delicacy in the leg. The affected area of the leg or arm that is swollen or damages might be hotter than expected, Skin that is red or stained, The veins close to the skin's surface might be bigger than normal [14].

If a person, have deep vein thrombosis (DVT), such person, have to take a medication, for example, Anticoagulants: Heparin, Warfarin, Rivaroxaban, Vena cava channels, Compression stockings, Exercise. Heparin is an anticoagulant (blood thinner agent) that inhibits the development of blood clusters. It creates its significant anticoagulant impact by inactivating thrombin and initiated factor $\mathrm{X}$ (factor $\mathrm{Xa}$ ) through an antithrombin (AT)- dependant mechanism. Heparin ties to AT through a high-partiality pentasaccharide, which is available on about $33 \%$ of heparin atoms [13] Warfarin is an anticoagulant agent typically used to inhibit blood clump development just as relocation. Warfarin hinders the vitamin $\mathrm{K}$ synthesis of biologically active form of the calcium dependant clotting factors II, VII, IX and X, just as the administrative elements protein $\mathrm{C}$, protein $\mathrm{S}$, and protein $Z$ [15]. Rivaroxaban is an anticoagulant and the primary orally dynamic direct factor Xa inhibitor. In contrast to warfarin, routine lab checking of INR is not important. Rivaroxaban restrains both free Factor Xa and Factor $\mathrm{Xa}$ bound in the prothrombinase complex. It is an exceptionally particular direct Factor $\mathrm{Xa}$ inhibitor with oral bioavailability and fast onset of action[16,17].

\section{METHODOLOG Y}

A hospital based descriptive observational study was conducted on the 100 patients who were reported with Deep Vein Thrombosis at tertiary care hospital SMBBMUH Larkana.Before collection of data permission was obtained from Medical Superintendent of teaching hospital of SMBBMUH Larkana via office letter No.D.Ph/847.Only those patients were included in the study whose age from 18years to 65 years. Only those patients were included in the study which wasreported with DVT. 
Comparative Analysis of Compliance between Rivaroxaban with Heparin and Warfarin in the Management of Deep Vein Thrombosis at Tertiary Care Hospital, Larkana

children were not included in the study. The study not comprises on same gender of patients. This research analysis was carried for 06 months.

This study has been conducted by filling up the questionnaires (specially designed) to monitor the compliance, non compliance and factors of non compliance for the patients associated with drugs used for the management of DVT.A series of questions were asked from reported patients regarding symptoms, compliance and side effects.
Finally the results were analyzed through descriptive analysis by using descriptive statistics.

\section{RESULTS}

In Table 1, Compliance and non compliance with Rivaroxaban was given, out of 33 patients, 25 patients were compliant with Rivaroxaban only 08 patients were non compliant with Rivaroxaban.

Table 1. Factors of Non-Compliance Reported in Patients (Rivaroxaban).

\begin{tabular}{|c|c|c|c|}
\hline S. No & Variables & Frequency & Percentage \\
\hline 1 & Compliance & 25 & $75.8 \%$ \\
\hline 2 & Non compliance & 08 & $24.2 \%$ \\
\hline 3 & Total & 33 & $100 \%$ \\
\hline
\end{tabular}

In Table 2, factors of non compliance were given, it was observed that among non compliant factor majority of patients were non compliant with Rivaroxaban due to prolong therapy, where as less common non compliant factor with Rivaroxaban were cost and polypharmacy.

Table 2. Compliance and Non-Compliance with Heparin.

\begin{tabular}{|c|c|c|c|}
\hline S.No & Factors & Frequency(n=8) & Percentage \\
\hline 1 & Cost & 1 & $12.5 \%$ \\
\hline 2 & Poly pharmacy & 1 & $12.5 \%$ \\
\hline 3 & Side effects & 2 & $25 \%$ \\
\hline 4 & Prolong Therapy & 4 & $50 \%$ \\
\hline
\end{tabular}

In Table 3, Compliance and non compliance with heparin was given, out of 22 patients only 03 patients were compliant where as majority of patients were non compliant with heparin.

Table 3. Factors of Non-Compliance Reported in Patients (Heparin).

\begin{tabular}{|c|c|c|c|}
\hline S. No & Variables & Frequency & Percentage \\
\hline 1 & Compliance & 03 & $3.6 \%$ \\
\hline 2 & Non compliance & 19 & $86.4 \%$ \\
\hline 3 & Total & 22 & $100 \%$ \\
\hline
\end{tabular}

In Table 4, non compliance factors with heparin were given. It was observed that most common non compliant factor with heparin was availability in Injectable form, where as less common non compliant factor was diet restriction.

Table 4. Compliance and Non-Compliance with Warfarin.

\begin{tabular}{|c|c|c|c|}
\hline S.No & Factors & Frequency(n=19) & percentage \\
\hline 1 & Monitoring & 5 & $26.3 \%$ \\
\hline 2 & Diet Restriction & 2 & $10.4 \%$ \\
\hline 3 & Injectable & 7 & $37 \%$ \\
\hline 4 & Adverse drug reactions & 5 & $26.3 \%$ \\
\hline
\end{tabular}


Comparative Analysis of Compliance between Rivaroxaban with Heparin and Warfarin in the Management of Deep Vein Thrombosis at Tertiary Care Hospital, Larkana

In Table 5, Compliance and non compliance with warfarin was given, out of 45 patients only 19 patients were compliant, where as 26 patients were non compliant with warfarin.

Table 5. Compliance and Non Compliance in Warfarin Taken Patients.

\begin{tabular}{|c|c|c|c|}
\hline S. No & Variables & Frequency & Percentage \\
\hline 1 & Compliance & 19 & $42.2 \%$ \\
\hline 2 & Non compliance & 26 & $57.8 \%$ \\
\hline 3 & Total & 45 & $100 \%$ \\
\hline
\end{tabular}

In Table 6, factors of non compliance were given, it was observed that most common non compliant factor was cost, where as less common noncompliant factor was adverse drug reaction.

Table 6. Factors of Non-Compliance.

\begin{tabular}{|c|c|c|c|}
\hline S.No & Factors of non Compliance & Frequency $(\mathbf{n = 2 6})$ & Percentage \\
\hline 1 & Cost & 09 & $34.7 \%$ \\
\hline 2 & Poly pharmacy & 08 & $30.8 \%$ \\
\hline 3 & Adverse drug reactions & 04 & $15.3 \%$ \\
\hline 4 & Prolong Therapy & 05 & $19.2 \%$ \\
\hline
\end{tabular}

\section{DISCUSSION}

Deep vein thrombosis (DVT) is one of the most important manifestation of venous thromboembolism. It is also an important reason of increasing the morbidity and mortality especially in hospitalized patients. It is very difficult to diagnose that not only increases its rate of mortality but also increase the uncertainty of its prevalence throughout the world [12]. Although, different studies reported the lower incidence of DVT in Asian countries in contrast to western countries but lack of recent researches on DVT in Asian countries is one of the major reason of reporting lower incidence of DVT. Lack of research on DVT patients increases the chances of poor diagnosis, prognosis of diseases, increasing morbidity and mortality.

Therefore, current descriptive observational research was designed in setting of tertiary care hospital of Larkana, where diagnosed patients of DVT were enrolled from medicine department and evaluated for commonly reported clinical sign and symptoms of DVT, patients drug compliance with Heparin, Warfarin and Rivaroxaban drugs and associated noncompliance factors with these antithrombotic drugs.

In this research study 100 patients of DVT were assessed, among which greater part of DVT patients were male (79\%) patients and remaining were female $(21 \%)$ patients. Comparable examination by Amiwero, C., et al., additionally detailed the $62.5 \%$ male DVT patients and $37.9 \%$ female DVT patients [10]. Another comparative investigation led in Pakistan by Zamir, Q., et al., additionally announced the $59 \%$ male DVT patients and $41 \%$ female DVT patients. Another Pakistani investigation by Arsh, An., et al., additionally announced the a lot higher 75.7 male DVT patients and lower $24.3 \%$ female DVT patients [12]. The entirety of the comparative investigations are indicating that male patients are for the most part experiencing DVT when contrasted with female patients.

In current research the drug compliance with rivaroxaban was present in (54.5\%) patients followed by warfarin drug compliance in $(42.5 \%)$ and drug compliance with heparin was $(0.0 \%)$ DVT patients and patients. A similar study by Kang, J. M., et al., reported the overall drug compliance $93.8 \%$ with antithrombotic drugs, whereas drug compliance with rivaroxaban was $100.0 \%$ and warfarin drug compliance was $93.8 \%$ [18]. Similarly, different other studies such as; Lazo-Langner, A., et al., compared the heparin and rivaroxaban, Deitelzweig, S., et al., compared the warfarin and rivaroxaban [20], Al Khateep, Y. M., et al. (2019) compared the warfarin and rivaroxaban [19] and Piati, P. K., et al. (2019) 
compared the heparin, warfarin and rivaroxaban [21] and reported the higher drug compliance with rivaroxaban followed by heparin and warfarin.

\section{CONCLUSION}

The study concluded that out of 100 patients, male patients observed more than female and mostly patients perform indoor jobs. Prevalence of DVT is high, about $53 \%$ patient were suffering from DVT during 03 months. It was found that mostly patient non compliance observed with heparin as compare to warfarin and rivaroxaban. The cost, prolong therapy, adverse drug reaction, diet restriction and monitoring are more common factors of non compliance in DVT patients. Over all the compliance rate of Rivaroxaban was more as compared to warfarin and heparin.

\section{REFERENCES}

1. Verhamme $P$, Bounameaux H. Direct Oral Anticoagulants for Acute Venous Thromboembolism: Closing the Circle? Circulation 2016; 129: 725 7https://doi.org/10.1161/CIRCULATIONAHA.113.0 07478.

2. Parker, K., \& Thachil, J. The use of direct oral anticoagulants in chronic kidney disease. British Journal of Haematology. 2018; 183(2): 170184.doi: 10.1111/bjh.15564.

3. Blech S, Ebner T, Ludwig Schwellinger E, Stangier J, Roth W. Th e metabolism and disposition of the oral direct thrombin inhibitor, dabigatran, in humans. Drug MetabDispos. 2015; 36: 386 - 99. DOI: 10.1124/dmd.107.01983.

4. Naringrekar, H., Sun, J., Ko, C., \& Rodgers, S. K.. It's Not All Deep Vein Thrombosis: Sonography of the Painful Lower Extremity With Multimodality Correlation. Journal of Ultrasound in Medicine. 2019; 38(4): 1075-1089.doi: 10.1002/jum.14776.

5. Cann AJ. Cardiovascular diseases. In: Kumar P, Clark M (eds). Clinical Medicine, 5th edn. WB Saunders: UK, 2015, pp 701-832.

6. Seifi, A., Dengler, B., Martinez, P., \& Godoy, D. A. Pulmonary embolism in severe traumatic brain injury. Journal of Clinical Neuroscience. 2018; 57 : 46-50.doi: 10.1016/j.jocn.2018.08.042.

7. Aziz I. Frequency of post operative deep vein thrombosis in highrisk surgical patients. J Coll Physicians Surg Pak. 2013; 15: 299-301. DOl: 05.2005/jcpsp.299301.
8. Kruger, P. C., Eikelboom, J. W., Douketis, J. D., \& Hankey, G. J.. Deep vein thrombosis: update on diagnosis and management. Medical Journal of Australia. 2019: 210(11): 516524.doi.org/10.5694/mja2.50201.

9. Burness, C. B., \& Perry, C. M. Rivaroxaban: a review of its use in the treatment of deep vein thrombosis or pulmonary embolism and the prevention of recurrent venous thromboembolism. Drugs. $\quad 2014$; 74(2): 243-262.DOI: 10.1007/s40265-013-0174-4.

10. Amiwero C, Campbell LA, Prescott RJ. A reappraisal of warfarin control in the treatment of deep vein thrombosis and/or pulmonary embolism. African health sciences. 2009;9(3).

11. Heidbuchel $H$, Verhamme $P$, Alings $M$, Antz $M$, Hacke W, Oldgren J, Sinnaeve P, Camm AJ, Kirchh of P. EHRA practical guide on the use of new oral anticoagulants in patients with nonvalvular atrial fi brillation: executive summary. Eur Heart J. 2013; 34: 2094 - 106. doi: 10.1093/europace/euv309.

12. Zamir, Q., Shah, A. R., Bhatti, A. M., \&Wajid, A. A. Frequency of proven risk factors for deep vein thrombosis in clinical patients: Results of a study on patients being treated at a tertiary care hospital in Rawalpindi, Pakistan. JPMA. The Journal of the Pakistan Medical Association. 2015; 65(1); 110112. PMID:25831693.

13. Agnelli G, Buller HR, Cohen A, Curto M, Gallus AS, Johnson $M$, Masiukiewicz $U$, Pak $R$, Thompson J, Raskob GE, Weitz JI; AMPLIFY Investigators. Oral apixaban for the treatment of acute venous thromboembolism. N Engl J Med. 2013; 369: 799 - 808. doi: 10.1056/NEJMoa1302507.

14. Ruff CT, Giugliano RP, Braunwald E, Hoff man EB, Deenadayalu N, Ezekowitz MD, Camm AJ, Weitz JI, Lewis BS, Parkhomenko A, Yamashita T, Antman EM. Comparison of the efficacy and safety of new oral anticoagulants with warfarin in patients with atrial $\mathrm{fi}$ brillation: a meta-analysis of randomized trials. Lancet 2013; S0140 - 6736 (13): 62343 - $0 . d o i$ 10.1016/S01406736(13)62343-0.

15. Liberati A, Altman DG, Tetzlaff J, Mulrow C, Gøtzsche PC, loannidis JP, Clarke M, Devereaux PJ, Kleijnen J, Moher D. Th e PRISMA statement for reporting systematic reviews and metaanalyses of studies that evaluate health care interventions: explanation and elaboration. Ann Intern Med. 2009; 151: W65 94.doi.org/10.1136/bmj.b2700. 
16. Hokusai-VTE Investigators. Edoxaban versus warfarin for the treatment of symptomatic venous thromboembolism. N Engl J Med. 2013 Oct 10;369:1406-15. doi: 10.1056/NEJMoa1306638.

17. Hoaglin DC, Hawkins N, Jansenjp, Scott DA, Itzler R, Cappellerijc, Boersma C, Thompson D, Larholt $\mathrm{KM}$, Diaz M, Barrett $\mathrm{A}$. conducting indirecttreatment-comparison and network-meta-analysis studies: report of the ispor task force on indirect treatment comparisons good research practices: part 2. value health. 2011; 14: 429 - 37.DOI: 10.1016/j.jval.2011.01.011.

18. Kang, J. M., Park, K. H., Ahn, S., Cho, S., Han, A., Lee, $T$ and Min, S. K. Rivaroxaban after thrombolysis in Acuteiliofemoral Venous thrombosis: A Randomized, open-labeled, Multicenter trial. Scientific Reports. 2019; 9(1): 18.doi.org/10.1038/s41598-019-56887.

19. Al Khateep, Y. M., Zaid, N. A., \& Salim, O. R. Comparative study of safety and effectiveness of rivaroxaban and warfarin in patients with acute deep venous thrombosis. The Egyptian Journal of Surgery. 2019; 38(2): 245.DOI: 10.4103/ejs.ejs_183_18.
20. Deitelzweig S, Kline J, Margolis JM, Raut M, Tran O, Smith D, Crivera C, Bookhart B, Schein J, Olson W. Comparison of rivaroxaban or warfarin use for venous thromboembolism on inpatient length of stay. Journal of the American College of Cardiology. .2065doi/abs/10.1016/S0735-1097.

21. Piati PK, Peres AK, de Andrade DO, Jorge MA, Toregeani JF. Analysis of recanalization of deep venous thrombosis: a comparative study of patients treated with warfarin vs. rivaroxaban. Jornal vascular brasileiro. 2019;18. 